\title{
Relevance of biomarkers across different neurodegenerative diseases
}

\author{
Alexander J. Ehrenberg ${ }^{1,2,3^{*}}$, Ayesha Khatun ${ }^{4}$,Emma Coomans ${ }^{5}$, Matthew J. Betts ${ }^{6,7}$, Federica Capraro ${ }^{8,9}$, \\ Elisabeth H. Thijssen ${ }^{1,10}$, Konstantin Senkevich ${ }^{11,12}$, Tehmina Bharucha ${ }^{13}$, Mehrsa Jafarpour ${ }^{14}$, Peter N. E. Young ${ }^{15,16}$, \\ William Jagust ${ }^{3,17}$, Stephen F. Carter ${ }^{18,19}$, Tammaryn Lashley ${ }^{14,20}$, Lea T. Grinberg ${ }^{1,21,22}$, Joana B. Pereira ${ }^{23,24}$, \\ Niklas Mattsson-Carlgren ${ }^{15,16}$, Nicholas J. Ashton ${ }^{15,16,25,26}$, Jörg Hanrieder ${ }^{14,15}$, Henrik Zetterberg ${ }^{14,15,27,28}$, \\ Michael Schöll ${ }^{14,15,24}$ and Ross W. Paterson ${ }^{4}$
}

\begin{abstract}
Background: The panel of fluid- and imaging-based biomarkers available for neurodegenerative disease research is growing and has the potential to close important gaps in research and the clinic. With this growth and increasing use, appropriate implementation and interpretation are paramount. Various biomarkers feature nuanced differences in strengths, limitations, and biases that must be considered when investigating disease etiology and clinical utility. For example, neuropathological investigations of Alzheimer's disease pathogenesis can fall in disagreement with conclusions reached by biomarker-based investigations. Considering the varied strengths, limitations, and biases of different research methodologies and approaches may help harmonize disciplines within the neurodegenerative disease field.

Purpose of review: Along with separate review articles covering fluid and imaging biomarkers in this issue of Alzheimer's Research and Therapy, we present the result of a discussion from the 2019 Biomarkers in Neurodegenerative Diseases course at the University College London. Here, we discuss themes of biomarker use in neurodegenerative disease research, commenting on appropriate use, interpretation, and considerations for implementation across different neurodegenerative diseases. We also draw attention to areas where biomarker use can be combined with other disciplines to understand issues of pathophysiology and etiology underlying dementia. Lastly, we highlight novel modalities that have been proposed in the landscape of neurodegenerative disease research and care.
\end{abstract}

Keywords: Biomarkers, Neurodegenerative diseases, Alzheimer's disease, Tau, Amyloid, Neurofilament light chain, Magnetic resonance imaging, Positron emission tomography, Cerebrospinal fluid, Plasma biomarkers

\section{Background}

With 50 million individuals affected worldwide, neurodegenerative diseases remain without disease-modifying treatments. Neuropathological investigations are critical for closing intellectual gaps regarding pathophysiologic mechanisms, as postmortem examination serves as a gold

\footnotetext{
* Correspondence: alexander.ehrenberg@ucsf.edu

${ }^{1}$ Memory and Aging Center, Weill Institute for Neurosciences, University of California, San Francisco, San Francisco, CA, USA

${ }^{2}$ Department of Integrative Biology, University of California, Berkeley, Berkeley, CA, USA

Full list of author information is available at the end of the article
}

standard and provides adequate resolution to observe the elements of pathophysiological cascades. However, they are limited to cross-sectional assessment. The use of antemortem biomarkers renders possible the detection of hallmarks longitudinally, throughout disease stages. Even in situations where conclusions drawn from antemortem biomarkers might differ from postmortem observations, antemortem biomarkers still offer utility. Here, we will illustrate ways that evidence can be weighed to understand neurodegenerative diseases holistically, focusing on methodology and the limitations and strengths of different modalities. 
Despite sometimes indirect associations with lesions, neuropathologically validated biomarkers can be used to assess disease course, particularly as degeneration relates to clinical manifestations. For trials, biomarkers are of paramount importance. They are key for efficiently identifying and tracking cohorts by defining inclusion criteria and outcome variables [1]. As shown in a follow-up to an amyloid$\beta$ (A $\beta$ ) immunization trial [2], neuropathology can be informative for trials; however, the timelines associated with postmortem donation hinder drug development. As treatments emerge, biomarkers will become even more valuable as diagnostic tools.

There are numerous biomarkers for neurodegenerative diseases readily available or under development (Tables 1 , 2, 3 and 4). In this issue of Alzheimer's Research and Therapy, separate articles will discuss fluid (Obrocki et al.) and imaging (Young et al.) biomarkers for neurodegenerative diseases. Priming this, it is important to consider how one assesses the utility and biases of different modalities. We will discuss ways that biomarkers are utilized in neurodegenerative disease research and care, commenting on appropriate use, interpretation, and implementation. Finally, we will consider where major knowledge gaps lie and how novel biomarkers may fill them. This review will primarily focus on Alzheimer's disease, due to a significant deficit in biomarkers useful for other neurodegenerative diseases; however, we will comment on emerging techniques for other diseases. Many of the themes discussed here on utility can be readily applied across neurodegenerative diseases.

\section{Disease fundamentals}

Neurodegenerative diseases represent the confluence of a range of pathophysiologic cascades with associated clinical spectra. While typically defined by proteinopathic hallmarks, it is unclear whether these hallmarks are driving the disease or are themselves consequences of other underlying processes. $\mathrm{AD}$, frontotemporal lobar degeneration (FTLD), and Parkinson's disease are the most common neurodegenerative diseases. Overlapping diseases, otherwise known as co-pathologies, are frequent and have complex contributions to clinical phenotypes [3].

\section{Alzheimer's disease}

Alzheimer's disease (AD) is the most common cause of dementia with an incidence of 1700-2900/100,000 individuals per year in the USA [4]. AD is a dual proteinopathy characterized by the accumulation of tau neurofibrillary tangles and extracellular $A \beta$ plaques [5]. Postmortem studies indicate that $\mathrm{AD}$ features a long preclinical phase where tau lesions and associated neuronal loss first appear in the subcortical nuclei and begin to involve limbic regions with associated subjective cognitive decline and neuropsychiatric symptoms [1, 6-9]. Cortical tau lesions appear in later stages [7], which correlate with the prototypical amnestic Alzheimer's clinical syndrome $[1,10]$. Also in the preclinical phase, $A \beta$ lesions initially appear in the neocortical regions followed by the allocortical, then subcortical, and cerebellar involvement [11]. In contrast to tau lesions, the distribution of $A \beta$ is not significantly associated with symptoms [12]. Besides age, risk factors include cerebrovascular diseases, diabetes, hypertension, obesity, dyslipidemia, and genetic factors such as the APOE- 44 allele and TREM2 mutations $[13,14]$. Approximately $5 \%$ of cases have an age of onset under 65 and are referred to as early-onset $\mathrm{AD}$ cases. Familial AD, accounting for about $20 \%$ of early-onset cases and less than $1 \%$ of all $\mathrm{AD}$ cases, is mainly caused by rare, dominantly inherited PSEN1, PSEN2, or APP mutations (Table 5) [15-17].

\section{Parkinson's disease}

Synucleinopathies are the second most common neurodegenerative disease [18]. The most common clinical presentation of a synucleinopathy, Parkinson's disease (PD), has an estimated incidence of 10-18/100,000 individuals

Table 1 MRI biomarkers for neurodegenerative diseases

\begin{tabular}{|c|c|c|c|}
\hline Biomarker & Target & Advantages & Disadvantages \\
\hline 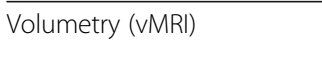 & $\begin{array}{l}\text { Whole brain/medial temporal } \\
\text { lobe, hippocampus }\end{array}$ & $\begin{array}{l}\text { Highly reproducible and sensitive } \\
\text { to disease-related changes }\end{array}$ & $\begin{array}{l}\text { Late-stage biomarker; cannot provide information } \\
\text { on the cause of atrophy }\end{array}$ \\
\hline Cortical thickness & Cerebral cortex & $\begin{array}{l}\text { May improve classification between } \\
\text { dementia subtypes }\end{array}$ & $\begin{array}{l}\text { Limited to neocortex; cannot be used to determine } \\
\text { the cause of atrophy }\end{array}$ \\
\hline Functional MRI (fMRI) & $\begin{array}{l}\text { Regional/network functional } \\
\text { activity }\end{array}$ & $\begin{array}{l}\text { Can evaluate robusticity of networks } \\
\text { at resting state and during tasks }\end{array}$ & $\begin{array}{l}\text { Reproducibility and influence of vasculature } \\
\text { unclear }\end{array}$ \\
\hline FLAIR/T2 imaging & White matter lesions & Highly sensitive & Cannot determine the cause of the lesion \\
\hline $\begin{array}{l}\text { T2*/susceptibility-weighted } \\
\text { imaging }\end{array}$ & Microbleeds/myelin/iron & $\begin{array}{l}\text { Microbleed location can aid } \\
\text { diagnosis }\end{array}$ & $\begin{array}{l}\text { Undesirable artifacts at air/tissue interfaces; few } \\
\text { longitudinal studies to date }\end{array}$ \\
\hline Diffusion tensor imaging & White matter & $\begin{array}{l}\text { Highly sensitive to white matter } \\
\text { damage }\end{array}$ & $\begin{array}{l}\text { Fairly low resolution and sensitive to artifacts from } \\
\text { water diffusion; particularly sensitive to movements }\end{array}$ \\
\hline Neuromelanin-sensitive & $\begin{array}{l}\text { Locus coeruleus, substantia } \\
\text { nigra }\end{array}$ & $\begin{array}{l}\text { Sensitive to noradrenergic and } \\
\text { dopaminergic subcortical nuclei }\end{array}$ & Semi-quantitative assessment/not disease specific \\
\hline
\end{tabular}


Table 2 PET biomarkers for neurodegenerative diseases

\begin{tabular}{|c|c|c|c|}
\hline Biomarker & Target & Advantages & Disadvantages \\
\hline${ }^{18} \mathrm{~F}-\mathrm{FDG}$ & $\begin{array}{l}\text { Glucose } \\
\text { metabolism }\end{array}$ & $\begin{array}{l}\text { Capable of detecting dysfunction that has not necessarily } \\
\text { involved atrophy; well-validated for clinical research }\end{array}$ & $\begin{array}{l}\text { Variability in methods of analysis between } \\
\text { studies/centers }\end{array}$ \\
\hline${ }^{18} \mathrm{~F}-\mathrm{FDDNP}$ & AD lesions & ${ }^{18} \mathrm{~F}$ half-life does not require on-site cyclotron & Does not differentiate $A \beta$ or tau aggregations \\
\hline${ }^{11} \mathrm{C}-\mathrm{PBB} 3$ & Tau lesions & $\begin{array}{l}\text { Sensitive to both AD-type tau aggregations and non-AD } \\
\text { tau aggregations; correlates with clinical progression }\end{array}$ & $\begin{array}{l}\text { Short half-life of }{ }^{11} \mathrm{C} \text {; relatively low affinity } \\
\text { compared to other tau markers; non-specific } \\
\text { binding }\end{array}$ \\
\hline $\begin{array}{l}{ }^{18} \mathrm{~F}-\mathrm{AV} 1451 \\
\text { (flortaucipir) }\end{array}$ & Tau lesions & $\begin{array}{l}\text { High affinity to aggregated tau; distribution of binding } \\
\text { reflects clinical presentations; }{ }^{18} \mathrm{~F} \text { half-life does not require } \\
\text { on-site cyclotron }\end{array}$ & $\begin{array}{l}\text { Off-target binding to neuromelanin and choroid } \\
\text { plexus; poor reliability in early NFT stages; preferential } \\
\text { binding to mixed 3R/4R tau rather than isolated } \\
\text { 3R or } 4 R \text { tau }\end{array}$ \\
\hline${ }^{18} \mathrm{~F}-\mathrm{GTP} 1$ & Tau lesions & $\begin{array}{l}\text { Ligand binding maps to known distribution of } \mathrm{AD} \text {-tau } \\
\text { aggregations; }{ }^{18} \mathrm{~F} \text { half-life does not require on-site cyclotron }\end{array}$ & $\begin{array}{l}\text { Yet to be fully validated; possible high non-specific } \\
\text { binding in basal ganglia }\end{array}$ \\
\hline${ }^{18} \mathrm{~F}-\mathrm{MK} 6240$ & Tau lesions & $\begin{array}{l}\text { Extremely high binding affinity to tau aggregations; good } \\
\text { brain delivery and washout; }{ }^{18} \mathrm{~F} \text { half-life does not require } \\
\text { on-site cyclotron }\end{array}$ & $\begin{array}{l}\text { Likely preferential binding to mixed } 3 R / 4 R \text { tau rather } \\
\text { than isolated } 3 R \text { or } 4 R \text { tau; off-target binding to } \\
\text { neuromelanin }\end{array}$ \\
\hline${ }^{18} \mathrm{~F}-\mathrm{RO} 6958948$ & Tau lesions & $\begin{array}{l}\text { High binding affinity to tau aggregations; preliminary } \\
\text { study shows longitudinal increases in } A D ;{ }^{18} \mathrm{~F} \text { half-life } \\
\text { does not require on-site cyclotron }\end{array}$ & $\begin{array}{l}\text { Yet to be fully validated; no significant binding in } \\
3 R \text { or } 4 R \text { tauopathies }\end{array}$ \\
\hline${ }^{18} \mathrm{~F}-\mathrm{THK} 5351$ & Tau lesions & $\begin{array}{l}\text { High binding affinity to tau over } A \beta \text { aggregations; }{ }^{18} \mathrm{~F} \\
\text { half-life does not require on-site cyclotron }\end{array}$ & $\begin{array}{l}\text { High non-specific retention in the subcortical white } \\
\text { matter; high MOA-B binding }\end{array}$ \\
\hline${ }^{18} \mathrm{~F}-\mathrm{THK} 5105$ & Tau lesions & $\begin{array}{l}\text { High binding affinity to tau over } A \beta \text { aggregations; }{ }^{18} \mathrm{~F} \\
\text { half-life does not require on-site cyclotron }\end{array}$ & $\begin{array}{l}\text { High non-specific retention in the subcortical white } \\
\text { matter; inferior signal-to-background ratio }\end{array}$ \\
\hline${ }^{18} \mathrm{~F}-\mathrm{THK} 523$ & Tau lesions & $\begin{array}{l}\text { High binding affinity to tau over } A \beta \text { aggregations; }{ }^{18} \mathrm{~F} \\
\text { half-life does not require on-site cyclotron }\end{array}$ & $\begin{array}{l}\text { High non-specific retention in the subcortical white } \\
\text { matter; poor in vivo visualization of tau deposition }\end{array}$ \\
\hline${ }^{18} \mathrm{~F}-\mathrm{PI} 2620$ & Tau lesions & $\begin{array}{l}\text { Binds to both } 3 R / 4 R \text { mix tau and } 3 R \text { tau (Pick's disease); } \\
\text { high binding affinity to tau over } A \beta \text { aggregations and } \\
\text { MOA-A/MOA-B; }{ }^{18} \mathrm{~F} \text { half-life does not require on-site } \\
\text { cyclotron }\end{array}$ & Yet to be fully validated \\
\hline${ }^{18}$ F-PM-PBB3 & Tau lesions & $\begin{array}{l}\text { Indication that ligand is sensitive to both } \mathrm{AD} \text { and } \\
\text { non- } \mathrm{AD} \text { tauopathies; little binding to MOA-A and } \\
\mathrm{MOA}-\mathrm{B} ;{ }^{18} \mathrm{~F} \text { half-life does not require on-site cyclotron }\end{array}$ & $\begin{array}{l}\text { Yet to be fully validated, particularly in non-AD } \\
\text { tauopathies }\end{array}$ \\
\hline${ }^{11} \mathrm{C}-\mathrm{PiB}$ & $\begin{array}{l}\text { Amyloid- } \beta \\
\text { aggregations }\end{array}$ & $\begin{array}{l}\text { High affinity to fibrillar } A \beta \text {; best studied of available } \\
A \beta \text { PET tracers }\end{array}$ & $\begin{array}{l}\text { Short half-life of }{ }^{11} C_{\text {; }} \text { not specific to } A D \text { amyloidosis/ } \\
\text { binds to CAA }\end{array}$ \\
\hline${ }^{18} \mathrm{~F}-\mathrm{AV}-45$ & $\begin{array}{l}\text { Amyloid- } \beta \\
\text { aggregations }\end{array}$ & $\begin{array}{l}\text { High affinity to fibrillar } A \beta ;{ }^{18} \mathrm{~F} \text { half-life does not require } \\
\text { on-site cyclotron }\end{array}$ & Not specific to $A D$ amyloidosis \\
\hline $\begin{array}{l}{ }^{18} \text { F-BAY94-9172 } \\
\text { (florbetaben) }\end{array}$ & $\begin{array}{l}\text { Amyloid- } \beta \\
\text { aggregations }\end{array}$ & $\begin{array}{l}\text { High affinity to fibrillar } A \beta ;{ }^{18} \mathrm{~F} \text { half-life does not require } \\
\text { on-site cyclotron }\end{array}$ & Not specific to $A D$ amyloidosis \\
\hline $\begin{array}{l}{ }^{18} \mathrm{~F}-\mathrm{GE} 067 \\
\text { (flutemetamol) }\end{array}$ & $\begin{array}{l}\text { Amyloid- } \beta \\
\text { aggregations }\end{array}$ & $\begin{array}{l}\text { High affinity to fibrillar } A \beta ;{ }^{18} \mathrm{~F} \text { half-life does not require } \\
\text { on-site cyclotron }\end{array}$ & Not specific to $A D$ amyloidosis \\
\hline${ }^{18} \mathrm{~F}-\mathrm{NAV} 4694$ & $\begin{array}{l}\text { Amyloid- } \beta \\
\text { aggregations }\end{array}$ & $\begin{array}{l}\text { Excellent agreement with }{ }^{11} \mathrm{C}-\mathrm{PiB} ;{ }^{18} \mathrm{~F} \text { half-life does not } \\
\text { require on-site cyclotron }\end{array}$ & Not specific to $A D$ amyloidosis \\
\hline${ }^{11}$ C-UCB-J & $\begin{array}{l}\text { Synapses } \\
(\text { SV2A) }\end{array}$ & High affinity to protein expressed on synapses & $\begin{array}{l}\text { Short half-life of }{ }^{11} \mathrm{C} \text {; relatively new tracer and not } \\
\text { well-validated in dementia populations }\end{array}$ \\
\hline
\end{tabular}

Abbreviations: PET positron emission tomography, FTD frontotemporal dementia, MOA-B monoamine oxidase B, PiB Pittsburg Compound-B, CAA cerebral amyloid angiopathy, FDG fluorodeoxyglucose, SV2A synaptic vesicle glycoprotein $2 \mathrm{~A}$

per year in the USA [19]. Synucleinopathies feature the aggregation of $\alpha$-synuclein in the form of Lewy bodies starting subcortically, spreading into limbic and neocortical regions [20]. Generally, synucleinopathies present as PD, PD dementia, or dementia with Lewy bodies, which collectively feature varying degrees of behavioral, cognitive, and autonomous symptoms on top of motor dysfunction. Mutations in a number of genes (Table 5) have been linked to synucleinopathies [10, 21], as has pesticide exposure and traumatic brain injury [22].

\section{Frontotemporal lobar degeneration}

FTLD is nearly as prevalent as early-onset AD in dementia cases below the age of 65 with an incidence of 1.6$4.1 / 100,000$ individuals annually in the USA and Europe $[23,24]$. FTLD describes a spectrum of diseases 
Table 3 CSF biomarkers for neurodegenerative diseases

\begin{tabular}{|c|c|c|c|}
\hline Biomarker & Target & Advantages & Disadvantages \\
\hline$\overline{A \beta 42}$ & Amyloid- $\beta$ peptides & Strong correlation with ${ }^{11} \mathrm{C}-\mathrm{PiB}$ PET status & Different cutoff values used in different labs \\
\hline$A \beta 40$ & Amyloid- $\beta$ peptides & Added value when combined with $A \beta 42$ & Not a clinically meaningful biomarker in isolation \\
\hline$A \beta 42 / A \beta 40$ ratio & Amyloid- $\beta$ peptides & $\begin{array}{l}\text { Stronger diagnostic and prognostic value } \\
\text { than } A \beta 42 \text { alone }\end{array}$ & Not yet widely implemented \\
\hline$A \beta 42 / A \beta 38$ ratio & Amyloid- $\beta$ peptides & $\begin{array}{l}\text { Stronger diagnostic and prognostic value } \\
\text { than } A \beta 42 \text { alone }\end{array}$ & Not yet widely implemented \\
\hline $\mathrm{t}-\mathrm{Tau}$ & Tau peptides & Reasonably sensitive for late-stage AD & Poor specificity, not clinically useful in isolation \\
\hline p-Thr181 tau & Tau peptides & Reasonably sensitive for late-stage AD & Poor specificity, not clinically useful in isolation \\
\hline NfL & White matter damage & Indicates the presence of neurodegeneration & Increased in multiple neurodegenerative diseases \\
\hline
\end{tabular}

Abbreviations: $A \beta$ amyloid $-\beta, N f L$ neurofilament light chain

characterized by vacuolation, gliosis, and neuronal loss in the external cortical layers of predominantly frontal and temporal neocortices and features the accumulation of tau, TDP-43, or fused-in sarcoma, which define the FTLD subtype $[25,26]$. FTLD is associated with a spectrum of frontotemporal dementia (FTD) syndromes ranging from behavioral, language, to motor variants. Amyotrophic lateral sclerosis (ALS) and other motor neuron diseases can be considered part of the FTLD spectrum due to common neuropathologic and genetic features [27]. Roughly one third of all FTD cases are familial [28].

\section{Huntington's disease}

Huntington's disease (HD) is a rare, autosomal dominant disease with an incidence of $0.16-0.94 / 100,000$ individuals annually [29]. The age of onset of symptoms is typically in the mid-40s but can range from as young as 2 to over 80 and features chorea with behavioral and cognitive symptoms [30]. While there is a correlation between CAG repeat length and age of onset [31,32], there is a high degree of variability making the predictive power of CAG repeat size poor, illustrating the complexity involved with treating HD. HD features progressive neuronal loss and astrogliosis in the striatum [33] as well as significant degeneration of the cortical regions, cerebellum, and brainstem nuclei [34]. While the huntingtin polyglutamate expansion leads to protein aggregation and transcriptional dysregulation, the mechanisms tying this to neuron loss are unclear.

\section{Prion diseases}

Prion diseases are characterized by spongiform encephalopathy with underlying neuronal loss, gliosis, and aggregation of the prion protein $(\mathrm{PrP})$ encoded by the PRNP gene [35]. PrP distinguishes prion diseases from other neurodegenerative diseases that may feature prionlike mechanisms, whereby misfolded amyloidogenic proteins spread throughout the brain via seeding aggregation processes. Several genetic, sporadic, and acquired/ zoonotic forms of prion diseases exist with sporadic Creutzfeldt-Jakob disease (sCJD), accounting for roughly $85 \%$ of cases [36]. With a mortality rate of $1.5-2$ individuals per million, $\mathrm{sCJD}$ is an extremely rare disease with an incidence rate that is difficult to ascertain [36]. Relevant clinical features include rapid cognitive decline,

Table 4 Blood biomarkers for neurodegenerative diseases

\begin{tabular}{|c|c|c|c|}
\hline Biomarker & Target & Advantages & Disadvantages \\
\hline $\begin{array}{l}\mathrm{A} \beta 42 / \mathrm{A} \beta 40 \\
\text { ratio }\end{array}$ & Amyloid- $\beta$ peptides & $\begin{array}{l}\text { Automated platform available for } \\
\text { measurements }\end{array}$ & $\begin{array}{l}\text { Difference in values between disease groups too small } \\
\text { to be used as a diagnostic tool. Levels can be affected } \\
\text { by pattern change from monomer to protofibrils in blood. }\end{array}$ \\
\hline MDS-OA $\beta$ & Amyloid- $\beta$ oligomers & $\begin{array}{l}\text { Differentiates AD patients from } \mathrm{HC} \text { with high } \\
\text { sensitivity and specificity, not affected by } \\
\text { pattern change in the blood }\end{array}$ & $\begin{array}{l}\text { Poorly validated and limited availability of technology } \\
\text { relative to ELISA-based methods }\end{array}$ \\
\hline IIR assay & $\begin{array}{l}\text { Amyloid a-helix versus } \\
\beta \text {-sheet form }\end{array}$ & $\begin{array}{l}\text { Detects biophysical properties of pathologic } \\
\text { forms of amyloid instead of just concentrations }\end{array}$ & $\begin{array}{l}\text { Poorly validated and limited availability of technology } \\
\text { relative to ELISA-based methods }\end{array}$ \\
\hline p-Thr181 tau & Tau peptides & Can accurately predict ${ }^{11} \mathrm{C}-\mathrm{PiB}$ PET status & $\begin{array}{l}\text { Does not differentiate between tauopathies other than } \\
\text { AD }\end{array}$ \\
\hline t-Tau & Tau peptides & $\begin{array}{l}\text { Automated platform available for } \\
\text { measurements }\end{array}$ & Large overlap between diagnostic groups \\
\hline NfL & White matter damage & $\begin{array}{l}\text { Indicates the presence of neurodegeneration; } \\
\text { strong correlation with CSF NfL }\end{array}$ & Increased in multiple neurodegenerative diseases \\
\hline
\end{tabular}


Table 5 Genetic biomarkers for neurodegenerative diseases

\begin{tabular}{llll}
\hline Gene & Protein & Associated Syndrome(s) & Reference \\
\hline APP & Amyloid precursor protein & EOAD (familial), CAA & Tanzi et al., 1987 [15] \\
PSEN1 & Presenilin 1 & EOAD (familial) & Sherrington et al., 1995 [16] \\
PSEN2 & Presenilin 2 & EOAD (familial) & Levy-Lahad et al., 1995 [17] \\
MAPT & MAPT & bvFTD, PSP & Hutton et al., 1998 [18]; Poorkaj et al., 1998 [19] \\
C9orf72 & C9orf72 & bvFTD, ALS & Renton et al., 2011 [20] \\
GRN & Progranulin & bvFTD, CBS & Gass et al., 2006 [21] \\
VCP & Valosin-containing protein & ALS & Johnson et al., 2010 [22] \\
TARDBP & TDP-43 & ALS & Shreedharan et al., 2008 [23] \\
SOD1 & Superoxide dismutase 1 & ALS & Rosen et al., 1993 [24] \\
FUS & Fused-in sarcoma & ALS & Kwiatkowski et al., 2009 [25]; Vance et al., 2009 [26] \\
HTT & Huntingtin & HD & HDCRG, 1993 [27] \\
SNCA & a-synuclein & PD, DLB, MSA & Kruger et al., 1998 [28] \\
GBA & B-glucocerebrosidase & PD, DLB, Gaucher & Sidransky and Lopez, 2012 [29] \\
PRNP & Prion protein & Prion & Liao et al., 1986 [30]; Kretzschmar et al., 1986 [31]; Hsiao et al., 1989 [32] \\
APOE (E4 allele) & Apolioporotein-E & AD (risk factor) & Corder et al., 1993 [33]; Saunders et al., 1993 [34] \\
TREM2 & TREM2 & AD (risk factor) & Guerreiro et al., 2013 [35]; Jonsson and Stafansson, 2013 [36] \\
\hline
\end{tabular}

Abbreviations: EOAD, Early-onset Alzheimer's disease; MAPT, Microtubule associated protein tau; CAA, Cerebral amyloid angiopathy; bvFTD, Behavioral-variant frontotemporal dementia; PSP, progressive supranuclear palsy; ALS, Amyotrophic Lateral Sclerosis; TDP-43, Transactive response DNA binding protein 43 kDa; FUS, Fusedin Sarcoma; CBS, corticobasal syndrome; HD, Huntington's disease; PD, Parkinson's disease; DLB, Dementia with Lewy bodies; MSA, multiple system atrophy; AD, Alzheimer's disease; TREM2, Triggering receptor expressed on myeloid cells 2

myoclonus, akinetic mutism, visual and cerebellar difficulties, and pyramidal or extrapyramidal features. A definitive identification requires neuropathological confirmation with postmortem or biopsied tissue. Probable identification requires either an electroencephalogram, magnetic resonance imaging (MRI), or cerebrospinal fluid (CSF)-based biomarkers with the use of real-time quaking-induced conversion (RT-QuIC) preferred over 14-3-3 detection [37].

\section{In vivo biomarkers for the study of pathophysiology and etiology}

Decades of neuropathological studies augmented by novel biomedical tools have revealed that many complex, interrelated mechanisms underlie neurodegenerative diseases. A principle limitation of the cross-sectional nature of neuropathology is difficulty in assessing temporal relationships. Neuropathological investigations typically only observe end-stages; however, existing population-based cohorts can capture the full range of disease progression [38]. Detecting and addressing early phases of pathophysiological cascades are likely key for successful therapeutics; thus, a granular understanding of the early underlying biology and the identification of biomarkers representing these changes is paramount.

Given the clear etiology and sometimes predictable age of onset, several studies have focused on hereditary neurodegenerative diseases to investigate early disease stages. For example, positron emission tomography (PET) imaging studies of familial $A D$ cases have suggested that brain $A \beta$ deposition begins up to 20 years before clinical symptoms, while cortical tau deposition arises roughly 6 years before onset $[39,40]$. Similarly, biomarker studies of FTLD mutation carriers suggest that pathological changes start decades before symptoms [41]. These studies demonstrate that a latency period exists prior to clinical decline which should be targeted therapeutically, confirming neuropathological observations. There is evidence that plasma $A \beta 42 /$ 40 is sensitive to preclinical amyloidosis, providing a more economical means than CSF or PET to identify participants in trials focused on early stages [42].

Curiously, conclusions from in vivo studies of the relative onset of $A \beta$ and tau lesions in $A D$ often conflict with investigations using large postmortem case series that indicate that tau lesions occur prior to $A \beta$ deposition in the brain $[6,7]$. This may be due to biases in the design of eventbased modeling approaches with biomarkers. Young and colleagues [43] found that CSF levels of total tau and phosphorylated tau become abnormal prior to CSF levels of A $\beta 42$, concurring with postmortem studies. It was not until they isolated the cohort to those who were already $A \beta+$, $\mathrm{APOE}_{+}$, or $\mathrm{A} \beta+$ and $\mathrm{APOE}+$, applying data-driven autopsy-validated cutoffs, which the sequence of biomarker changes recapitulated those typically found in biomarker studies. Further, differences between investigators regarding thresholds and characterization of what belongs to "clinically meaningful" disease spectra will affect the conclusions drawn. To illustrate, Weigand and colleagues found that $\mathrm{A} \beta$ PET-negative and tau PET-positive individuals tend to 
present with subtle cognitive changes, which they interpret to represent early AD-related changes [44]. That is to say that tau PET-positive and A $\beta$ PET-negative individuals belong to an early phase of the disease spectra. This argument is strengthened by evidence that tau PET distribution predicts subsequent atrophy, whereas A $\beta$ PET does not [45]. At the same time, others would characterize tau PETpositive and $A \beta$ PET-negative individuals as having "suspected non-Alzheimer disease pathophysiology," implying that they belong to a different disease spectrum instead of a, rather, early phase of $\mathrm{AD}$ that may later feature both lesions [1]. As the field remains split regarding the precise, biological definition of AD stages, interdisciplinary efforts must harmonize observations by acknowledging their varied, but complementary, strengths and limitations.

Information gleaned from longitudinal studies has been used to construct models of multiple biomarkers. The widely recognized "Jack curves" [46], for example, were explicitly intended to provide a "model of $[\mathrm{AD}]$ biomarkers" to help stage cases in vivo [46], setting a precedent for the 2018 guidelines for an in vivo research definition of $\mathrm{AD}$ [3]. However, the curves should not be interpreted as providing a comprehensive model of $\mathrm{AD}$ pathophysiology and are subject to revision as biomarkers become more advanced [46].

\section{Challenges in interpreting pathobiology}

When combining biomarkers in a study, it is also important to account for differences in how they represent respective disease hallmarks. Importantly, the biomarkers must have a comparable target engagement with their respective hallmarks or, at the least, empirical measures of target engagement to adjust for different sensitivities. For fluid biomarkers, the kinetics of how biomarkers appear in the fluid samples (i.e., how a protein might be digested, processed, or passed into the CSF or blood) may differ and must be accounted for. While expensive and laborintensive, kinetics can be measured through in vivo labeling techniques [47] that track protein production and clearance. Significant technological gaps exist with the detection of soluble biomarkers in vivo. Of note, lipid peroxidation and metabolism have been implicated in neurodegenerative diseases [48], yet current tools limit the degree to which this can be monitored in vivo. Similarly, robust fluid biomarkers of blood-brain barrier function have been lacking, with several under development.

Idiosyncratic properties of pathophysiological processes can manifest misleading results in biomarker-based studies of pathophysiology. For PET, there is a heterogeneous uptake of different ligands throughout the brain, and differences in this uptake, off-target binding, and imaging sensitivity should be accounted for. In AD, early tau lesions begin in the brainstem nuclei followed by limbic involvement, whereas $A \beta$ lesions begin in the neocortical regions $[7,8,49]$. Several limitations with PET may lead to biases in detecting these two patterns. PET cameras are susceptible to partial volume effects and lack resolution to measure tau ligand binding in the subcortical regions, which are small but can have profound neurobiological and behavioral effects $[6,8,9,50-54]$. Lowe and colleagues demonstrated that tau PET positivity denotes individuals who, at autopsy, are all already at Braak stage IV [55], at which point many subcortical structures and limbic regions would already feature significant degeneration $[8,9,51]$. Further, a tau PET imaging study [56], with relatively low SUVR values for positivity, estimated the prevalence of Braak stage 0 individuals as roughly $55 \%$ of their study population $(n=161)$ while a population-based autopsy study [6] featured just $28 \%$ of the study population $(n=455)$ as Braak stage 0. Depending on the thresholds used, tau PET recapitulates the histological progression of tau lesions seen at autopsy; however, the thresholds set may render the tau PET "Braak stage" an underestimate of the true Braak stage at autopsy, particularly at early stages, as seen in these studies [56, 57]. Additionally, some of the first regions to feature protein aggregation in neurodegenerative diseases contain neuromelanin, which many PET ligands will non-specifically bind to $[58,59]$. By contrast, the signal from ${ }^{11} \mathrm{C}-\mathrm{PiB}$ and other ligands targeting $\mathrm{A} \beta$ can detect early, neocortical involvement of plaques [60], making $A \beta$ easier to detect.

Other biological factors, including the significant impact of low-abundance hallmarks such as mutant huntingtin, synaptic proteins, and neurogranin should also be considered, as their low abundance may lead to underestimation of the roles these hallmarks play using event-based modeling approaches. To illustrate, differences in relative abundances of tau versus $A \beta$ lesions, due to tau tangles accumulating within cells and $A \beta$ occurring extracellularly, make the relative determination of proteinopathy onset difficult in vivo. The strengths of $\mathrm{A} \beta$ biomarkers may outweigh the weaknesses of tau biomarkers, potentially overrepresenting the relative involvement of $A \beta$ versus tau lesions at different $A D$ stages, especially in early stages. The development of biomarkers and studies with multidisciplinary, postmortem observations are needed to reconcile these issues.

Biomarkers are invaluable for elucidating pathophysiology with appropriate caution. Specific biological questions may call for different implementations of biomarkers, and establishing universal guidelines for their research use would be presumptuous. Biomarker status may be sensitive and specific to certain neuropathological diagnoses; however, one should not assume that clinical utility implies broadsweeping research utility or vice versa. In vivo, labeling approaches and high-resolution biomarker-neuropathology correlations are critical for assessing the validity of individual biomarkers as they relate to underlying lesions [47]. 
Unless the extent of the factors connecting lesions to the detection of their corresponding biomarkers is elaborated, one must be cautious when employing biomarkers in studies of disease etiology, particularly when comparing biomarkers with varied biases.

\section{Biomarkers for the study of disease intervention}

Rigorous validations of biomarkers through methods such as kinetics quantification [47] or postmortem correlation are necessary considerations for the selection of inclusion criteria and outcomes for clinical trials. Those trials that target underlying proteinopathy, such as the $\mathrm{A} \beta$-modifying drugs for the treatment of $\mathrm{AD}$, require an in vivo measurement of lesions to verify target engagement. By contrast, intervention studies that focus on specific symptoms of diseases, such as depression, may not require in vivo measurements of proteinopathy. Nevertheless, an operational, validated biomarker-based definition of different diseases is paramount for trials focused on disease-modifying therapies.

The 2018 NIA-AA guidelines for an in vivo research definition of $\mathrm{AD}$ set an outline for clinical trials based on a biomarker definition of AD [1]. The authors argue that since $A \beta$ and tau lesions, together with neurodegeneration, define $\mathrm{AD}$ postmortem, participants should be identified in vivo based on these hallmarks. There remains disagreement regarding which biomarkers can be used to identify these hallmarks, though. Biomarkers for FTLD, synucleinopathies, and other neurodegenerative diseases are underdeveloped or have not yet been fully validated so a similar biomarker definition of other neurodegenerative diseases has yet to be established.

$\mathrm{A} \beta$ and tau PET imaging could serve as useful outcomes in clinical trials due to their ability to detect regional changes in vivo preceding significant atrophy [61, 62]. The implementation of tau PET in tau-targeting therapies is particularly encouraged due to the target's associations with neurodegeneration and cognition [45, 63]. Further consideration regarding proteinopathy biomarker implementation in $\mathrm{AD}$ trials is warranted, though, as therapeutic changes in $A \beta$ load have not associated with clinical changes or neurodegeneration [2]. Fluid levels of neurofilament light chain (NfL) are candidate outcomes for trials as they correlate with cognitive status and atrophy; however, they are not specific to underlying proteinopathy and instead represent the presence of general neurodegeneration [64].

Similarly, therapeutic development for HD serves to benefit from biomarker development. Despite the existence of a highly specific and sensitive genetic marker [62, 65], it is difficult to predict the age of onset [30]. Furthermore, clinical trials cannot rely on genetic markers as they will not change following a therapeutic intervention. Decreased striatal uptake of phosphodiesterase-10 PET tracer [66], atrophy in
MRI [67], and plasma levels of IL-8, TNF- $\alpha$ [68], and NfL may be valuable markers for HD progression that could be used for evaluating the effectiveness of interventions.

Novel ultrasensitive immunoassays make blood biomarkers promising for the future as less invasive, costeffective screening instruments [69]. In $A D$, plasma $A \beta 42$ is decreased compared to controls [70, 71], and plasma $\mathrm{A} \beta 42 / 40$ is reduced in $\mathrm{A} \beta$ PET-positive individuals [72, 73]. Plasma NfL, which correlates with CSF NfL, may be useful for tracking neurodegeneration and associates with cognitive decline and atrophy [64, 74]. These require further validation but may serve as more accessible markers in the future [75]. Factors such as how plasma $A \beta$ levels change in response to disease-modifying therapies, exposure time to drugs, and harmonization of analytical methodology remain a challenge $[75,76]$. With well-characterized cohorts that now include A $\beta$ PET and CSF measures, the opportunity to use an "endophenotype" approach to discover peripheral markers of lesions is increasing. Pilot data from discovery mass spectrometry and large panel-based approaches suggest associations of many plasma proteins and metabolites with $\mathrm{AD}[65,77,78]$. However, these data should be interpreted with caution, as they are derived from multimarker panels with the mechanistic understanding of the associations lacking.

\section{Developing biomarkers for clinical use}

In individuals with suspected neurodegenerative diseases that lack known monogenic etiologies, biomarkers are currently used on an exclusionary basis to rule out other diseases and may be used to support a specific diagnosis of a neurodegenerative disease. Other biomarkers are in the pipeline for clinical validation and determination of clinical value.

For example, structural MRI can be used to exclude space-occupying lesions and assess patterns of atrophy that aids diagnoses made by neurological assessment. Functional MRI and ${ }^{18} \mathrm{~F}$-FDG PET can also be used to identify the affected brain regions and networks [10, 79, 80]. NfL is the best-established fluid marker for measuring neurodegeneration but has poor specificity [81]. A summary of currently available biomarkers that may hold clinical promise is provided in Tables 1, 2, 3 and 4.

Following the discovery and validation phases of biomarker development, standardization and clinical utility are key steps for clinical implementation. In these phases of biomarker development, key questions regarding optimal procedures, reproducibility, and elucidation of the biological relevance can be assessed. Further, these phases will determine the sensitivity and specificity of each biomarker to a given disease. For example, plasma NfL well represents the underlying neurodegeneration [74], but the consistency between labs is unclear and a great deal of overlap between diagnostic groups exists [81]. Another consideration in the 
standardization phase is the establishment of cutoffs for diagnostic thresholds. This requires a large study to assess biomarker values across diverse healthy and disease populations, accounting for possible differences in sample collection and analysis.

A further criterion for establishing biomarkers in clinical practice, even when biologically meaningful, is the utility for patient management which can determine financial coverage for the test. An ongoing study in the USA is examining how $\mathrm{A} \beta$ PET results influence patient management [82]. Preliminary results suggest that management is influenced by the use of A $\beta$ PET; however, the effects on the prognosis are not yet known [82].

\section{New frontiers in biomarkers}

In addition to the array of targets that can be detected by standard fluid and imaging biomarkers, other features of neurodegenerative diseases have been proposed as viable biomarkers of disease progression. One technique, the Multimer Detection System-Oligomeric A $\beta$, examines the tendency of plasma proteins to oligomerize, circumventing issues in measuring concentrations of $A \beta$ itself [83]. Another uses biophysical properties associated with the propensity of the amyloid protein to form $\beta$-sheets to measure blood levels with an immune-infrared sensor assay [84, 85]. In vivo measurement of an early-affected region, the locus coeruleus, is being explored as a viable early biomarker using specialized MRI sequences and analysis [52]. In line with this, pupillometry is being explored as a measure of noradrenergic activity and, thus, locus coeruleus integrity [52]. Signal analysis from transcranial magnetic stimulation, electroencephalography, or magnetoencephalography has also shown promise as a biomarker of functional connectivity and may be sensitive to early changes [86-88]. Other functional readouts, such as sleep polysomnography and app-based digital phenotyping assessments have been proposed as early biomarkers as well [89-91].

\section{Conclusions}

In combination with basic science and neuropathologic examination, biomarkers are invaluable for building a narrative on pathophysiology, clinical etiology, and strategies for interventions. As there are numerous ways biomarkers may be informative, caution must be exercised to ensure appropriate interpretation given the varied limitations of different modalities. Importantly, a significant gap remains for biomarker availability in non-AD neurodegenerative diseases. As the field works towards therapies for dementias, there continues to be a grave need for novel biomarkers, improved development of existing tools, standardization, and improved accessibility for clinical and research communities.

\section{Acknowledgements}

AJE thanks Renaud La Joie, PhD (UCSF Memory and Aging Center) for the thoughtful discussion on topics covered in this manuscript.

\section{Authors' contributions}

AJE coordinated the writing of the review and was responsible for integrating the input from all authors. AK contributed to sections involving clinical trial implementation and fluid biomarkers. EC contributed to sections involving PET imaging. MJB contributed to sections involving MRI. FC contributed to sections involving epidemiology. EHT and MJ contributed to sections involving fluid biomarkers. KS contributed to sections involving biomarker implementation. TB contributed to sections involving novel tools for fluid biomarkers. PNEY contributed to sections involving neuroimaging. WJ, SFC, and JBP provided intellectual guidance on sections related to neuroimaging. TL and LTG provided intellectual guidance on sections related to neuropathology. NM, NJA, JH, and $\mathrm{HZ}$ provided intellectual guidance on sections related to fluid biomarkers. MS provided guidance on the coordination of authors and neuroimaging biomarkers. RWP provided guidance on the coordination of authors and served as the senior author. All authors reviewed and approved the final manuscript.

\section{Funding}

The Biomarker Teaching course was funded by and supported by the National Institute for Health Research University College London Hospitals Biomedical Research Centre. AJE and LTG received support for this review from institutional grant numbers K24 AG053435, U54 NS100717, and P50 AG023501 from the NIH National Institute on Aging. MJB received support from the Human Brain Project (SP3 WP 3.3.1). JBP received support from the Swedish Research Council, Alzheimerfonden and Hjärnfonden. TL is supported by an Alzheimer's Research UK senior fellowship. HZ is a Wallenberg Academy fellow supported by grants from the Swedish Research Council (\#2018-02532), the European Research Council (\#681712), the Swedish State Support for Clinical Research (\#ALFGBG-720931), and the UK Dementia Research Institute at UCL. MS is funded by the Knut and Alice Wallenberg Foundation (Wallenberg Centre for Molecular and Translational Medicine), the Swedish Research Council, the Swedish Alzheimer Foundation, the Swedish State Support for Clinical Research, and the Association for FTD UK. RWP is supported by an NIHR academic clinical lectureship.

\section{Availability of data and materials}

Data sharing is not applicable to this article as no datasets were generated or analyzed during the current study.

Ethics approval and consent to participate Not applicable.

\section{Consent for publication}

Not applicable.

\section{Competing interests}

AJE has accepted compensation as a consultant to Epiodyne Inc. WJJ is a consultant for Genentech, Novartis, and Bioclinica. NM serves as a consultant for the Alzheimer's Disease Neuroimaging Initiative. LTG has received research support from AVID Radiopharmecuticals and Eli Lily. HZ has served at scientific advisory boards for Roche Diagnostics, Wave, Samumed, and CogRx; has given lectures in symposia sponsored by Alzecure and Biogen; and is a co-founder of the Brain Biomarker Solutions in Gothenburg AB, a GU Ventures-based platform company at the University of Gothenburg. MS has served at a scientific advisory board for Servier. All other authors declare that they have no competing interests.

\section{Author details}

${ }^{1}$ Memory and Aging Center, Weill Institute for Neurosciences, University of California, San Francisco, San Francisco, CA, USA. ${ }^{2}$ Department of Integrative Biology, University of California, Berkeley, Berkeley, CA, USA. ${ }^{3}$ Helen Wills Neuroscience Institute, University of California, Berkeley, Berkeley, CA, USA. ${ }^{4}$ Dementia Research Centre, University College London Institute of Neurology, London, UK. ${ }^{5}$ Department of Radiology \& Nuclear Medicine, Amsterdam UMC, location VUmc, Amsterdam Neuroscience, Amsterdam, The Netherlands. ${ }^{6}$ German Center for Neurodegenerative Diseases (DZNE), 
Magdeburg, Germany. ${ }^{7}$ Institute of Cognitive Neurology and Dementia Research, Otto von Guericke University Magdeburg, Magdeburg, Germany. ${ }^{8}$ The Francis Crick Institute, London, UK. ${ }^{9}$ Department of Neuromuscular Diseases, University College London Queen Square Institute of Neurology, London, UK. ${ }^{10}$ Department of Clinical Chemistry, Amsterdam UMC, Amsterdam, The Netherlands. ${ }^{1}$ Petersburg Nuclear Physics Institute names by B.P. Konstantinov of National Research Center, Kurchatov Institute, St. Petersburg, Russia. ${ }^{12}$ First Pavlov State Medical University of St. Petersburg, St. Petersburg, Russia. ${ }^{13}$ Oxford Glycobiology Institute, Department of Biochemistry, University of Oxford, Oxford, UK. ${ }^{14}$ Department of Neurodegenerative Disease, UCL Queen Square, Institute of Neurology, University College London, London, UK. ${ }^{15}$ Department of Psychiatry and Neurochemistry, Sahlgrenska Academy at the University of Gothenburg, Mölndal, Sweden. ${ }^{16}$ Wallenberg Center for Molecular and Translational Medicine, Lund University, Lund, Sweden. ${ }^{17}$ Molecular Biophysics and Integrated Bioimaging, Lawrence Berkeley National Laboratory, Berkeley, CA, USA. ${ }^{18}$ Department of Psychiatry, School of Clinical Medicine, University of Cambridge, Cambridge, UK. ${ }^{19}$ Wolfson Molecular Imaging Centre, Division of Neuroscience and Experimental Psychology, University of Manchester, Manchester, UK. ${ }^{20}$ Queen Square Brain Bank for Neurological Disorders, UCL Queen Square Institute of Neurology, London, UK. ${ }^{21}$ University of São Paulo Medical School, São Paulo, Brazil. ${ }^{22}$ Global Brain Health Institute, San Francisco, CA, USA. ${ }^{23}$ Division of Clinical Geriatrics, Department of Neurobiology, Care Sciences and Society, Karolinska Institutet, Stockholm, Sweden. ${ }^{24}$ Clinical Memory Research Unit, Department of Clinical Sciences, Faculty of Medicine, Lund University, Lund, Sweden. ${ }^{25}$ King's College London, Institute of Psychiatry, Psychology \& Neuroscience, Maurice Wohl Clinical Neuroscience Institute, London, UK. ${ }^{26}$ NIHR Biomedical Research Centre for Mental Health \& Biomedical Research Unit for Dementia at South London \& Maudsley NHS Foundation, London, UK. ${ }^{27}$ Clinical Neurochemistry Laboratory, Sahlgrenska University Hospital, Mölndal, Sweden. ${ }^{28}$ UK Dementia Research Institute at University College London, London, UK.

Received: 8 November 2019 Accepted: 16 March 2020 Published online: 13 May 2020

\section{References}

1. Jack CR Jr, Bennett DA, Blennow K, Carrillo MC, Dunn B, Haeberlein SB, et al. NIA-AA Research Framework: toward a biological definition of Alzheimer's disease. Alzheimers Dement. 2018;14(4):535-62.

2. Nicoll JAR, Buckland GR, Harrison $\mathrm{CH}$, Page $\mathrm{A}$, Harris $\mathrm{S}$, Love $\mathrm{S}$, et al. Persistent neuropathological effects 14 years following amyloid-beta immunization in Alzheimer's disease. Brain. 2019;142(7):2113-26.

3. Robinson JL, Lee EB, Xie SX, Rennert L, Suh E, Bredenberg C, et al. Neurodegenerative disease concomitant proteinopathies are prevalent, agerelated and APOE4-associated. Brain. 2018;141(7):2181-93.

4. Rajan KB, Weuve J, Barnes LL, Wilson RS, Evans DA. Prevalence and incidence of clinically diagnosed Alzheimer's disease dementia from 1994 to 2012 in a population study. Alzheimers Dement. 2019;15(1):1-7.

5. Montine TJ, Phelps CH, Beach TG, Bigio EH, Cairns NJ, Dickson DW, et al. National Institute on Aging-Alzheimer's Association guidelines for the neuropathologic assessment of Alzheimer's disease: a practical approach. Acta Neuropathol. 2012;123(1):1-11.

6. Ehrenberg AJ, Suemoto CK, Franca Resende EP, Petersen C, Leite REP, Rodriguez RD, et al. Neuropathologic correlates of psychiatric symptoms in Alzheimer's disease. J Alzheimers Dis. 2018;66(1):115-26.

7. Braak H, Thal DR, Ghebremedhin E, Del Tredici K. Stages of the pathologic process in Alzheimer disease: age categories from 1 to 100 years. J Neuropathol Exp Neurol. 2011;70(11):960-9.

8. Ehrenberg AJ, Nguy AK, Theofilas P, Dunlop S, Suemoto CK, Di Lorenzo Alho AT, et al. Quantifying the accretion of hyperphosphorylated tau in the locus coeruleus and dorsal raphe nucleus: the pathological building blocks of early Alzheimer's disease. Neuropathol Appl Neurobiol. 2017;43(5):393-408.

9. Stratmann K, Heinsen H, Korf HW, Del Turco D, Ghebremedhin E, Seidel K, et al. Precortical phase of Alzheimer's disease (AD)-related tau cytoskeletal pathology. Brain Pathol. 2016;26(3):371-86.

10. Elahi FM, Miller BL. A clinicopathological approach to the diagnosis of dementia. Nat Rev Neurol. 2017;13(8):457-76.

11. Thal DR, Rub U, Orantes M, Braak H. Phases of Aß-deposition in the human brain and its relevance for the development of AD. Neurology. 2002;58(12): 1791-800.
12. Giannakopoulos P, Herrmann FR, Bussiere T, Bouras C, Kovari E, Perl DP, et al. Tangle and neuron numbers, but not amyloid load, predict cognitive status in Alzheimer's disease. Neurology. 2003;60(9):1495-500.

13. Yaffe K. Modifiable risk factors and prevention of dementia: what is the latest evidence? JAMA Intern Med. 2018;178(2):281-2.

14. Livingston G, Sommerlad A, Orgeta V, Costafreda SG, Huntley J, Ames D, et al. Dementia prevention, intervention, and care. Lancet. 2017;390(10113): 2673-734.

15. Tanzi RE, Gusella JF, Watkins PC, Bruns GA, St George-Hyslop P, Van Keuren $M L$, et al. Amyloid beta protein gene: $C D N A, m R N A$ distribution, and genetic linkage near the Alzheimer locus. Science. 1987;235(4791):880-4.

16. Silva MVF, Loures CMG, Alves LCV, de Souza LC, Borges KBG, Carvalho MDG. Alzheimer's disease: risk factors and potentially protective measures. J Biomed Sci. 2019;26(1):33.

17. Bekris $L M, Y u C E$, Bird TD, Tsuang DW. Genetics of Alzheimer disease. J Geriatr Psychiatry Neurol. 2010;23(4):213-27.

18. Dorsey ER, Constantinescu R, Thompson JP, Biglan KM, Holloway RG, Kieburtz K, et al. Projected number of people with Parkinson disease in the most populous nations, 2005 through 2030. Neurology. 2007;68(5):384-6.

19. Van Den Eeden SK, Tanner CM, Bernstein AL, Fross RD, Leimpeter A, Bloch DA, et al. Incidence of Parkinson's disease: variation by age, gender, and race/ethnicity. Am J Epidemiol. 2003;157(11):1015-22.

20. Braak H, Ghebremedhin E, Rub U, Bratzke H, Del Tredici K. Stages in the development of Parkinson's disease-related pathology. Cell Tissue Res. 2004; 318(1):121-34.

21. Nussbaum RL. Genetics of synucleinopathies. Cold Spring Harb Perspect Med. 2018;8:a024109.

22. Noyce AJ, Bestwick JP, Silveira-Moriyama L, Hawkes CH, Giovannoni G, Lees AJ, et al. Meta-analysis of early nonmotor features and risk factors for Parkinson disease. Ann Neurol. 2012;72(6):893-901.

23. Coyle-Gilchrist IT, Dick KM, Patterson $K$, Vazquez Rodriquez P, Wehmann $E_{i}$ Wilcox A, et al. Prevalence, characteristics, and survival of frontotemporal lobar degeneration syndromes. Neurology. 2016;86(18):1736-43.

24. Knopman DS, Roberts RO. Estimating the number of persons with frontotemporal lobar degeneration in the US population. J Mol Neurosci. 2011:45(3):330-5.

25. Mackenzie IR, Neumann M, Cairns NJ, Munoz DG, Isaacs AM. Novel types of frontotemporal lobar degeneration: beyond tau and TDP-43. J Mol Neurosci. 2011;45(3):402-8.

26. Cairns NJ, Bigio EH, Mackenzie IR, Neumann M, Lee VM, Hatanpaa KJ, et al. Neuropathologic diagnostic and nosologic criteria for frontotemporal lobar degeneration: consensus of the Consortium for Frontotemporal Lobar Degeneration. Acta Neuropathol. 2007;114(1):5-22.

27. Karch CM, Wen N, Fan CC, Yokoyama JS, Kouri N, Ross OA, et al. Selective genetic overlap between amyotrophic lateral sclerosis and diseases of the frontotemporal dementia spectrum. JAMA Neurol. 2018;75(7):860-75.

28. Lashley T, Rohrer JD, Mead S, Revesz T. Review: an update on clinical, genetic and pathological aspects of frontotemporal lobar degenerations. Neuropathol Appl Neurobiol. 2015;41(7):858-81.

29. Pringsheim T, Wiltshire K, Day L, Dykeman J, Steeves T, Jette N. The incidence and prevalence of Huntington's disease: a systematic review and meta-analysis. Mov Disord. 2012;27(9):1083-91.

30. Myers RH. Huntington's disease genetics. NeuroRx. 2004;1 (2):255-62.

31. Group THsDCR. A novel gene containing a trinucleotide repeat that is expanded and unstable on Huntington's disease chromosomes. The Huntington's Disease Collaborative Research Group. Cell. 1993;72(6):971-83.

32. Duyao $M$, Ambrose $C$, Myers $R$, Novelletto A, Persichetti F, Frontali $M$, et al. Trinucleotide repeat length instability and age of onset in Huntington's disease. Nat Genet. 1993;4(4):387-92.

33. Vonsattel JP, Myers RH, Stevens TJ, Ferrante RJ, Bird ED, Richardson EP Jr. Neuropathological classification of Huntington's disease. J Neuropathol Exp Neurol. 1985;44(6):559-77.

34. Rub U, Seidel K, Heinsen H, Vonsattel JP, den Dunnen WF, Korf HW. Huntington's disease (HD): the neuropathology of a multisystem neurodegenerative disorder of the human brain. Brain Pathol. 2016;26(6): 726-40.

35. Hsiao K, Baker HF, Crow TJ, Poulter M, Owen F, Terwilliger JD, et al. Linkage of a prion protein missense variant to Gerstmann-Straussler syndrome. Nature. 1989;338(6213):342-5.

36. Mackenzie G, Will R. Creutzfeldt-Jakob disease: recent developments. F1000Res. 2017;6:2053. 
37. Peckeu L, Delasnerie-Laupretre N, Brandel JP, Salomon D, Sazdovitch V, Laplanche $J$, et al. Accuracy of diagnosis criteria in patients with suspected diagnosis of sporadic Creutzfeldt-Jakob disease and detection of 14-3-3 protein, France, 1992 to 2009. Euro Surveill. 2017;22:16-00715.

38. Grinberg LT, Ferretti RE, Farfel JM, Leite R, Pasqualucci CA, Rosemberg S, et al. Brain bank of the Brazilian aging brain study group - a milestone reached and more than 1,600 collected brains. Cell Tissue Bank. 2007;8(2):151-62.

39. Bateman RJ, Xiong C, Benzinger TL, Fagan AM, Goate A, Fox NC, et al. Clinical and biomarker changes in dominantly inherited Alzheimer's disease. N Engl J Med. 2012;367(9):795-804.

40. Quiroz YT, Sperling RA, Norton DJ, Baena A, Arboleda-Velasquez JF, Cosio D, et al. Association between amyloid and tau accumulation in young adults with autosomal dominant Alzheimer disease. JAMA Neurol. 2018;75(5):548-56.

41. Jiskoot LC, Panman JL, Meeter LH, Dopper EGP, Donker Kaat L, Franzen S, et al. Longitudinal multimodal MRI as prognostic and diagnostic biomarker in presymptomatic familial frontotemporal dementia. Brain. 2019;142(1):193-208.

42. Schindler SE, Bollinger JG, Ovod V, Mawuenyega KG, Li Y, Gordon BA, et al. High-precision plasma beta-amyloid $42 / 40$ predicts current and future brain amyloidosis. Neurology. 2019;93(17):e1647-e59.

43. Young AL, Oxtoby NP, Daga P, Cash DM, Fox NC, Ourselin S, et al. A datadriven model of biomarker changes in sporadic Alzheimer's disease. Brain. 2014;137(Pt 9):2564-77.

44. Weigand AJ, Bangen KJ, Thomas KR, Delano-Wood L, Gilbert PE, Brickman $\mathrm{AM}$, et al. Is tau in the absence of amyloid on the Alzheimer's continuum? a study of discordant PET positivity. Brain Communications. 2020;2:fcz046.

45. La Joie R, Visani AV, Baker SL, Brown JA, Bourakova V, Cha J, et al. Prospective longitudinal atrophy in Alzheimer's disease correlates with the intensity and topography of baseline tau-PET. Sci Transl Med. 2020;12:eaau5732.

46. Jack CR Jr, Knopman DS, Jagust WJ, Petersen RC, Weiner MW, Aisen PS, et al. Tracking pathophysiological processes in Alzheimer's disease: an updated hypothetical model of dynamic biomarkers. Lancet Neurol. 2013;12(2):207-16.

47. Paterson RW, Gabelle A, Lucey BP, Barthelemy NR, Leckey CA, Hirtz C, et al. SILK studies - capturing the turnover of proteins linked to neurodegenerative diseases. Nat Rev Neurol. 2019;15(7):419-27.

48. Reed T. Lipid peroxidation and neurodegenerative disease. Free Radic Biol Med. 2011;51(7):1302-19.

49. Braak H, Braak E. Neuropathological stageing of Alzheimer-related changes. Acta Neuropathol. 1991:82(4):239-59.

50. Wang YT, Edison P. Tau imaging in neurodegenerative diseases using positron emission tomography. Curr Neurol Neurosci Rep. 2019;19(7):45

51. Theofilas P, Ehrenberg AJ, Dunlop S, Di Lorenzo Alho AT, Nguy A, Leite REP, et al. Locus coeruleus volume and cell population changes during Alzheimer's disease progression: a stereological study in human postmortem brains with potential implication for early-stage biomarker discovery. Alzheimers Dement. 2017;13(3):236-46.

52. Betts MJ, Kirilina E, Otaduy MCG, Ivanov D, Acosta-Cabronero J, Callaghan $\mathrm{MF}$, et al. Locus coeruleus imaging as a biomarker for noradrenergic dysfunction in neurodegenerative diseases. Brain. 2019;142(9):2558-71.

53. Hoffman EJ, Huang SC, Phelps ME. Quantitation in positron emission computed tomography: 1. Effect of object size. J Comput Assist Tomogr. 1979;3(3):299-308.

54. Soret M, Bacharach SL, Buvat I. Partial-volume effect in PET tumor imaging. J Nucl Med. 2007:48(6):932-45.

55. Lowe VJ, Lundt ES, Albertson SM, Min HK, Fang P, Przybelski SA, et al. Taupositron emission tomography correlates with neuropathology findings. Alzheimers Dement. 2019.

56. Schwarz AJ, Yu P, Miller BB, Shcherbinin S, Dickson J, Navitsky M, et al. Regional profiles of the candidate tau PET ligand 18F-AV-1451 recapitulate key features of Braak histopathological stages. Brain. 2016;139(Pt 5):1539-50.

57. Maass A, Landau S, Baker SL, Horng A, Lockhart SN, La Joie R, et al. Comparison of multiple tau-PET measures as biomarkers in aging and Alzheimer's disease. Neuroimage. 2017;157:448-63.

58. Lemoine L, Leuzy A, Chiotis K, Rodriguez-Vieitez E, Nordberg A. Tau positron emission tomography imaging in tauopathies: the added hurdle of offtarget binding. Alzheimers Dement (Amst). 2018;10:232-6.

59. Scholl M, Maass A, Mattsson N, Ashton NJ, Blennow K, Zetterberg H, et al. Biomarkers for tau pathology. Mol Cell Neurosci. 2019;97:18-33.

60. La Joie R, Ayakta N, Seeley WW, Borys E, Boxer AL, DeCarli C, et al. Multisite study of the relationships between antemortem [(11)C]PIB-PET Centiloid values and postmortem measures of Alzheimer's disease neuropathology. Alzheimers Dement. 2019;15(2):205-16.
61. Ossenkoppele R, Prins ND, van Berckel BN. Amyloid imaging in clinical trials. Alzheimers Res Ther. 2013;5(4):36.

62. Ten Kate M, Ingala S, Schwarz AJ, Fox NC, Chetelat G, van Berckel BNM, et al. Secondary prevention of Alzheimer's dementia: neuroimaging contributions. Alzheimers Res Ther. 2018;10(1):112.

63. Harrison TM, La Joie R, Maass A, Baker SL, Swinnerton K, Fenton L, et al. Longitudinal tau accumulation and atrophy in aging and alzheimer disease. Ann Neurol. 2019;85(2):229-40.

64. Mattsson N, Andreasson U, Zetterberg H, Blennow K, Alzheimer's Disease Neuroimaging I. Association of plasma neurofilament light with neurodegeneration in patients with Alzheimer disease. JAMA Neurol. 2017;74(5):557-66.

65. Burnham SC, Rowe CC, Baker D, Bush Al, Doecke JD, Faux NG, et al. Predicting Alzheimer disease from a blood-based biomarker profile: a 54month follow-up. Neurology. 2016;87(11):1093-101.

66. Russell DS, Barret O, Jennings DL, Friedman JH, Tamagnan GD, Thomae D, et al. The phosphodiesterase 10 positron emission tomography tracer, [18F]MNI-659, as a novel biomarker for early Huntington disease. JAMA Neurol. 2014;71(12):1520-8.

67. Tabrizi SJ, Scahill Rl, Owen G, Durr A, Leavitt BR, Roos RA, et al. Predictors of phenotypic progression and disease onset in premanifest and early-stage Huntington's disease in the TRACK-HD study: analysis of 36-month observational data. Lancet Neurol. 2013;12(7):637-49.

68. Bjorkqvist M, Wild EJ, Thiele J, Silvestroni A, Andre R, Lahiri N, et al. A novel pathogenic pathway of immune activation detectable before clinical onset in Huntington's disease. J Exp Med. 2008;205(8):1869-77.

69. Rissin DM, Kan CW, Campbell TG, Howes SC, Fournier DR, Song L, et al. Single-molecule enzyme-linked immunosorbent assay detects serum proteins at subfemtomolar concentrations. Nat Biotechnol. 2010;28(6):595-9.

70. Nakamura A, Kaneko N, Villemagne VL, Kato T, Doecke J, Dore V, et al. High performance plasma amyloid-beta biomarkers for Alzheimer's disease. Nature. 2018;554(7691):249-54

71. Janelidze S, Stomrud E, Palmqvist S, Zetterberg H, van Westen D, Jeromin A, et al. Plasma beta-amyloid in Alzheimer's disease and vascular disease. Sci Rep. 2016;6:26801.

72. Verberk IMW, Slot RE, Verfaillie SCJ, Heijst H, Prins ND, van Berckel BNM, et al. Plasma amyloid as prescreener for the earliest Alzheimer pathological changes. Ann Neurol. 2018;84(5):648-58.

73. Ovod V, Ramsey KN, Mawuenyega KG, Bollinger JG, Hicks T, Schneider T, et al. Amyloid beta concentrations and stable isotope labeling kinetics of human plasma specific to central nervous system amyloidosis. Alzheimers Dement. 2017;13(8):841-9.

74. Ashton NJ, Leuzy A, Lim YM, Troakes C, Hortobagyi T, Hoglund K, et al. Increased plasma neurofilament light chain concentration correlates with severity of post-mortem neurofibrillary tangle pathology and neurodegeneration. Acta Neuropathol Commun. 2019;7(1):5.

75. Blennow K, Zetterberg H. Biomarkers for Alzheimer's disease: current status and prospects for the future. J Intern Med. 2018;284(6):643-63.

76. Ashton NJ, Scholl M, Heurling K, Gkanatsiou E, Portelius E, Hoglund K, et al. Update on biomarkers for amyloid pathology in Alzheimer's disease. Biomark Med. 2018;12(7):799-812

77. Ashton NJ, Nevado-Holgado AJ, Barber IS, Lynham S, Gupta V, Chatterjee P, et al. A plasma protein classifier for predicting amyloid burden for preclinical Alzheimer's disease. Sci Adv. 2019;5(2):eaau7220.

78. Voyle N, Kim M, Proitsi P, Ashton NJ, Baird AL, Bazenet C, et al. Blood metabolite markers of neocortical amyloid-beta burden: discovery and enrichment using candidate proteins. Transl Psychiatry. 2016;6:e719.

79. Seeley WW, Crawford RK, Zhou J, Miller BL, Greicius MD. Neurodegenerative diseases target large-scale human brain networks. Neuron. 2009;62(1):42-52.

80. Pereira JB, van Westen D, Stomrud E, Strandberg TO, Volpe G, Westman E, et al. Abnormal structural brain connectome in individuals with preclinical Alzheimer's disease. Cereb Cortex. 2018;28(10):3638-49.

81. Lewczuk P, Ermann N, Andreasson U, Schultheis C, Podhorna J, Spitzer P, et al. Plasma neurofilament light as a potential biomarker of neurodegeneration in Alzheimer's disease. Alzheimers Res Ther. 2018;10(1):71.

82. Rabinovici GD, Gatsonis C, Apgar C, Chaudhary K, Gareen I, Hanna L, et al. Association of amyloid positron emission tomography with subsequent change in clinical management among Medicare beneficiaries with mild cognitive impairment or dementia. JAMA. 2019;321(13):1286-94.

83. An SSA, Lee BS, Yu JS, Lim K, Kim GJ, Lee R, et al. Dynamic changes of oligomeric amyloid beta levels in plasma induced by spiked synthetic Abeta42. Alzheimers Res Ther. 2017;9(1):86. 
84. Nabers A, Perna L, Lange J, Mons U, Schartner J, Guldenhaupt J, et al. Amyloid blood biomarker detects Alzheimer's disease. EMBO Mol Med. 2018;10:e8763.

85. Nabers A, Ollesch J, Schartner J, Kotting C, Genius J, Hafermann H, et al. Amyloid-beta-secondary structure distribution in cerebrospinal fluid and blood measured by an immuno-infrared-sensor: a biomarker candidate for Alzheimer's disease. Anal Chem. 2016;88(5):2755-62.

86. Stam CJ. Use of magnetoencephalography (MEG) to study functional brain networks in neurodegenerative disorders. J Neurol Sci. 2010;289(1-2):128-34

87. McMackin R, Muthuraman M, Groppa S, Babiloni C, Taylor JP, Kiernan MC, et al. Measuring network disruption in neurodegenerative diseases: new approaches using signal analysis. J Neurol Neurosurg Psychiatry. 2019;90(9): 1011-20.

88. Rodrigues Brazete J, Gagnon JF, Postuma RB, Bertrand JA, Petit D, Montplaisir J. Electroencephalogram slowing predicts neurodegeneration in rapid eye movement sleep behavior disorder. Neurobiol Aging. 2016;37:74-81.

89. Winer JR, Mander BA, Helfrich RF, Maass A, Harrison TM, Baker SL, et al. Sleep as a potential biomarker of tau and beta-amyloid burden in the human brain. J Neurosci. 2019;39(32):6315-24.

90. Dagum P. Digital biomarkers of cognitive function. NPJ Digit Med. 2018;1:10.

91. Possin KL, Moskowitz T, Erlhoff SJ, Rogers KM, Johnson ET, Steele NZR, et al. The brain health assessment for detecting and diagnosing neurocognitive disorders. J Am Geriatr Soc. 2018;66(1):150-6.

\section{Publisher's Note}

Springer Nature remains neutral with regard to jurisdictional claims in published maps and institutional affiliations. 